\title{
MicroRNA-23b regulates nasopharyngeal carcinoma cell proliferation and metastasis by targeting E-cadherin
}

\author{
JUN-YING WANG ${ }^{*}$, XIAO-FENG LI* ${ }^{*}$ PEI-ZHONG LI, XIN ZHANG, YU XU and XIN JIN \\ Department of ENT, Huai'an First People's Hospital, Nanjing Medical University, Huai'an, Jiangsu 223300, P.R. China
}

Received November 5, 2014; Accepted October 15, 2015

DOI: $10.3892 / \mathrm{mmr} .2016 .5206$

\begin{abstract}
MicroRNA-23b (miR-23b) is important in tumor proliferation and metastasis. In this study, it was suggested that the levels of miR-23b were increased in nasopharyngeal carcinoma (NPC) tissues compared with the adjacent normal tissues. The present study aimed to explore the role of miR-23b upregulation in NPC. Functional studies demonstrated that inhibition of miR-23b could significantly suppress NPC cell proliferation, migration and invasion. An in vitro reporter assay suggested that E-cadherin is a direct target gene of miR-23b. Furthermore, the expression of miR-23b in NPC tissues was inversely correlated with that of E-cadherin. These findings provide evidence that miR-23b is key in promoting NPC cell proliferation, migration and invasion through targeting E-cadherin, and strongly suggests that an exogenous miR-23b inhibitor may have therapeutic value in treating NPC.
\end{abstract}

\section{Introduction}

Nasopharyngeal carcinoma (NPC) is the most common type of cancer originating in the nasopharynx, and has a higher incidence in certain regions of East Asia and Africa than in other parts of the world. NPC is caused by a combination of factors: Viral, environmental influences and heredity (1). It has been shown that NPC is sensitive to radiotherapy and chemotherapy, with a cure rate of $\sim 70 \%(2,3)$. The viral influence is associated with infection with Epstein-Barr virus (EBV) (4). EBV-encoded RNA signals are present in all NPC cells, and early diagnosis of the disease is possible through the detection of raised antibodies against EBV. However, a number of genes are reported to contribute to the risk of NPC according to studies regarding genetic linkage and association $(5,6)$.

Correspondence to: Dr Pei-Zhong Li, Department of ENT, Huai'an First People's Hospital, Nanjing Medical University, 6 Beijing Road West, Huai'an, Jiangsu 223300, P.R. China

E-mail: lipeizhong115@163.com

${ }^{*}$ Contributed equally

Key words: microRNA, microRNA-23b, E-cadherin, nasopharyngeal carcinoma
Therefore, separate efforts are required to investigate the underlying molecular mechanisms of carcinogenesis.

In recent years, a class of novel non-coding RNAs termed microRNAs (miRNAs) have been identified in plants and animals. MicroRNAs (miRNAs) are 18-26 nucleotides long and post-transcriptionally regulate gene expression in multicellular organisms by affecting the stability and translation of mRNAs. In the process of tumor formation, the abnormal expression or the loss of the dynamic balance between oncogenes and tumor suppressor genes leads to tumorigenesis and cancer development. miRNAs, important regulatory factors of gene expression, are also involved in tumor formation and progression. Considerable evidence has demonstrated critical functions of miRNAs in diverse biological processes, such as proliferation (7-15), apoptosis (16-23), angiogenesis (24-30), cell differentiation (31-33), adhesion and metastasis (34) of tumor cells. Therefore, downregulation of the expression of certain miRNAs may result in the development of cancer. Previous studies have confirmed the presence of cancer-specific miRNAs in numerous types of cancers, such as breast cancer (35), lung cancer (36) and hepatocellular carcinoma (37).

The incidence of NPC involves changes in the expression of oncogenes and tumor suppressor genes. The present study aimed to determine the effects of miR-23b on the phenotypes of NPC cells as well as identify its target genes, in order to investigate the molecular mechanisms underlying the involvement of miR-23b in the initiation and progression of NPC.

\section{Materials and methods}

Patient and samples. Samples were obtained from 17 patients (3 men and 14 women) with NPC who underwent complete resection at the Huai'an First People's Hospital from April 2010 to January 2014. NPC tissue biopsies were obtained at the time of diagnosis prior to any therapy, and the cancerous tissue sections were immediately frozen at $-80^{\circ} \mathrm{C}$ following removal from the patients. Regarding the primary tumor stage, 5 patients had a T1-2 stage and 12 patients had a T3-4 stage according to the 2008 Chinese staging system (38). In terms of clinical stage, 7 patients were in stage I-II and 7 patients in stage III-IV (information regarding the clinical stage of the remaining patients was unavailable). The clinicopathological characteristics of the patients with NPC are summarized in Table I. The present study was approved by the ethics 
committee of Huai'an First People's Hospital (Huai'an, China), and written-informed consent was obtained from all the study participants.

miRNA target prediction. TargetScan (http://www.targetscan. org/), PicTar (http://pictar.mdc-berlin.de/) and miRBase (http://www.mirbase.org/) were used to predict miRNA targets.

Cell culture and transfection. CNE1 and CNE2z cells $\left(1 \times 10^{6} / \mathrm{ml}\right.$; obtained from the department of ENT, Huai'an First People's Hospital) were cultured in RPMI-1640 (Gibco-BRL, Carlsbad, CA, USA) containing 10\% heat-inactivated fetal bovine serum (Gibco-BRL), $100 \mathrm{IU}$ penicillin/ml (Gibco-BRL) and $0.1 \mathrm{mg}$ streptomycin/ml (Gibco-BRL) in a humidified 5\% (v/v) atmosphere of $\mathrm{CO}_{2}$ at $37^{\circ} \mathrm{C}$. The cells were transfected with Lipofectamine 2000 (Invitrogen Life Technologies, Carlsbad, CA, USA), according to the manufacturer's instructions. Briefly, the cells were seeded $\left(1 \times 10^{6}\right)$ to $90 \%$ confluence at transfection, and $4 \mu \mathrm{l}$ of Lipofectamine 2000 were diluted in $250 \mu \mathrm{l}$ Opti-Minimal Essential Medium (MEM; Invitrogen Life Technologies). miR23b mimics, miR23b control, antisense oligonucleotides (ASO) miR23b, and ASO control ( $2 \mu \mathrm{g}$ of each; Guangzhou RiboBio Co., Ltd., Guangzhou, China) were then diluted in $250 \mu \mathrm{l}$ Opti-MEM, and the diluted DNA was further diluted with Lipofectamine 2000 (1:1 ratio). The solution was incubated for $5 \mathrm{~min}$ at room temperature, and the DNA-lipid complex was added to the cells.

Reverse transcription-quantitative polymerase chain reaction (RT-qPCR). To detect the relative level of transcription, RT-qPCR was performed. Briefly, cDNA was generated through reverse transcription using M-MLV reverse transcriptase (Promega Corporation, Madison, WI, USA) with $2 \mu \mathrm{g}$ large RNA extracted from the cells. Total RNA was separated into large and small RNAs, which were isolated using the mirVana miRNA Isolation kit (Invitrogen Life Technologies). cDNA $(1 \mu \mathrm{g})$ was used for the amplification of E-cadherin and $\beta$-actin, which was used as an endogenous control for the PCR reaction. PCR was performed under the following conditions: $94^{\circ} \mathrm{C}$ for $4 \mathrm{~min}$ followed by 40 cycles of $94^{\circ} \mathrm{C}$ for $1 \mathrm{~min}, 56^{\circ} \mathrm{C}$ for $1 \mathrm{~min}, 72^{\circ} \mathrm{C}$ for $1 \mathrm{~min}$, using an iQ5 Real-Time PCR detection system (Bio-Rad Laboratories, Inc., Hercules , CA, USA). The relative fold-change in the transcripts was calculated with the $2^{-\Delta \Delta \mathrm{Ct}}$ method (39). The primers used were as follows: E-cadherin forward, 5'-CAATCTCAAGCTCATGG-3', and reverse, 5'-CCATTCGTTCAAGTAGTC-3'; $\beta$-actin forward, 5'-ATGCCA ACACAGTGCTGTCTGG-3', and reverse, 5'-TACTCCTGCTTGCTGATCCACAT-3'; miR-23b forward, 5'-CGCGGCCGCTAGTATTATGTT-3', and reverse, 5'-CAC ATTTTAAAAAACATA-3'; and U6 forward, 5'-TGCGGG TGCTCGCTTCGGCAGC-3', and reverse, 5'-CCAGTGCAG GGTCCGAGGT-3'.

Western blotting. Cultured cells were lysed in radioimmunoprecipitation assay buffer (containing $0.1 \%$ SDS, $1 \%$ Triton $\mathrm{X}-100,1 \mathrm{mM} \mathrm{MgCl}$ and $10 \mathrm{mM}$ Tris-HCl; $\mathrm{pH}$ 7.4; Invitrogen Life Technologies) at $4^{\circ} \mathrm{C}$ for $25 \mathrm{~min}$. The lysates were collected and cleared by centrifugation at $10,000 \mathrm{x}$ g for $10 \mathrm{~min}$, and protein concentration was determined. Briefly, total cell
Table I. Clinicopathological features of the patients with nasopharyngeal carcinoma.

\begin{tabular}{lcc}
\hline Variable & No. of patients & Percentage \\
\hline Gender & & \\
Male & 14 & 82.36 \\
Female & 3 & 17.64 \\
Age & & \\
$\geq 46$ & 14 & 82.36 \\
$<46$ & 3 & 17.64 \\
Primary tumor stage & & \\
T1-2 & 5 & 29.41 \\
T3-4 & 12 & 70.59 \\
Clinical stage & & \\
I-II & 7 & 41,17 \\
III-IVa & 7 & 41,17 \\
\hline
\end{tabular}
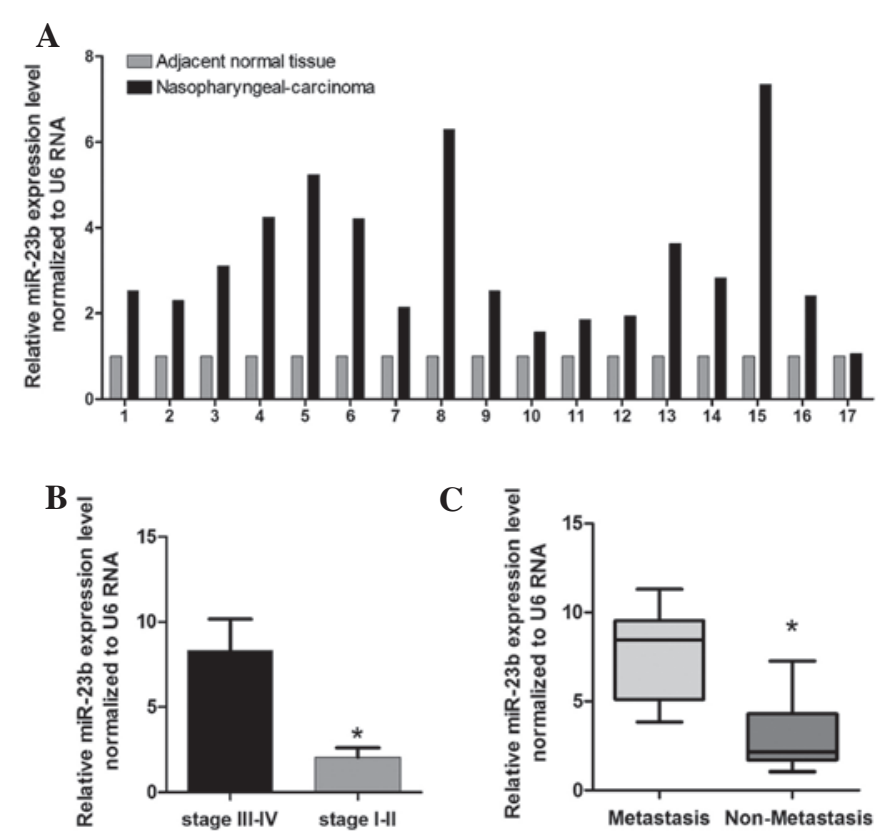

Figure 1. Identification of differential expression of miR-23b in human nasopharyngeal carcinoma. (A) RT-qPCR was used to detect miR-23b expression in 17 human nasopharyngeal carcinoma tissues and corresponding adjacent normal tissues. U6 snRNA was regarded as an endogenous normalizer and the relative miR-23b expression level of the 17 pairs of nasopharyngeal tissues (mean \pm standard deviation) is shown ( $\mathrm{P}<0.05$ ). (B) RT-qPCR was used to detect miR-23b expression in human nasopharyngeal carcinoma of different stages ("P $<0.05$ vs. stage III-IV tissue samples). (C) RT-qPCR was used to detect miR-23b expression in the metastatic and non-metastatic human nasopharyngeal carcinoma tissue samples ( $\mathrm{P}<0.05)$. miR, microRNA; RT-qPCR, reverse transcription-quantitative polymerase chain reaction.

lysates $(50 \mu \mathrm{g})$ were fractionated by $10 \%$ SDS-PAGE. Proteins were electroblotted onto nitrocellulose membranes (Bio-Rad Laboratories, Inc.). Nonspecific binding sites of membranes were saturated with 5\% skimmed milk in Tris-buffered saline with Tween-20 solution (TBST; $100 \mathrm{mmol} / \mathrm{l}$ Tris-Cl, $\mathrm{pH}$ 7.5; $150 \mathrm{mmol} / \mathrm{l} \mathrm{NaCl}$ and $0.1 \%$ Tween-20) and incubated for $2 \mathrm{~h}$ with antibodies at room temperature. The following antibodies were used: Monoclonal mouse anti-human E-cadherin (1:100; 

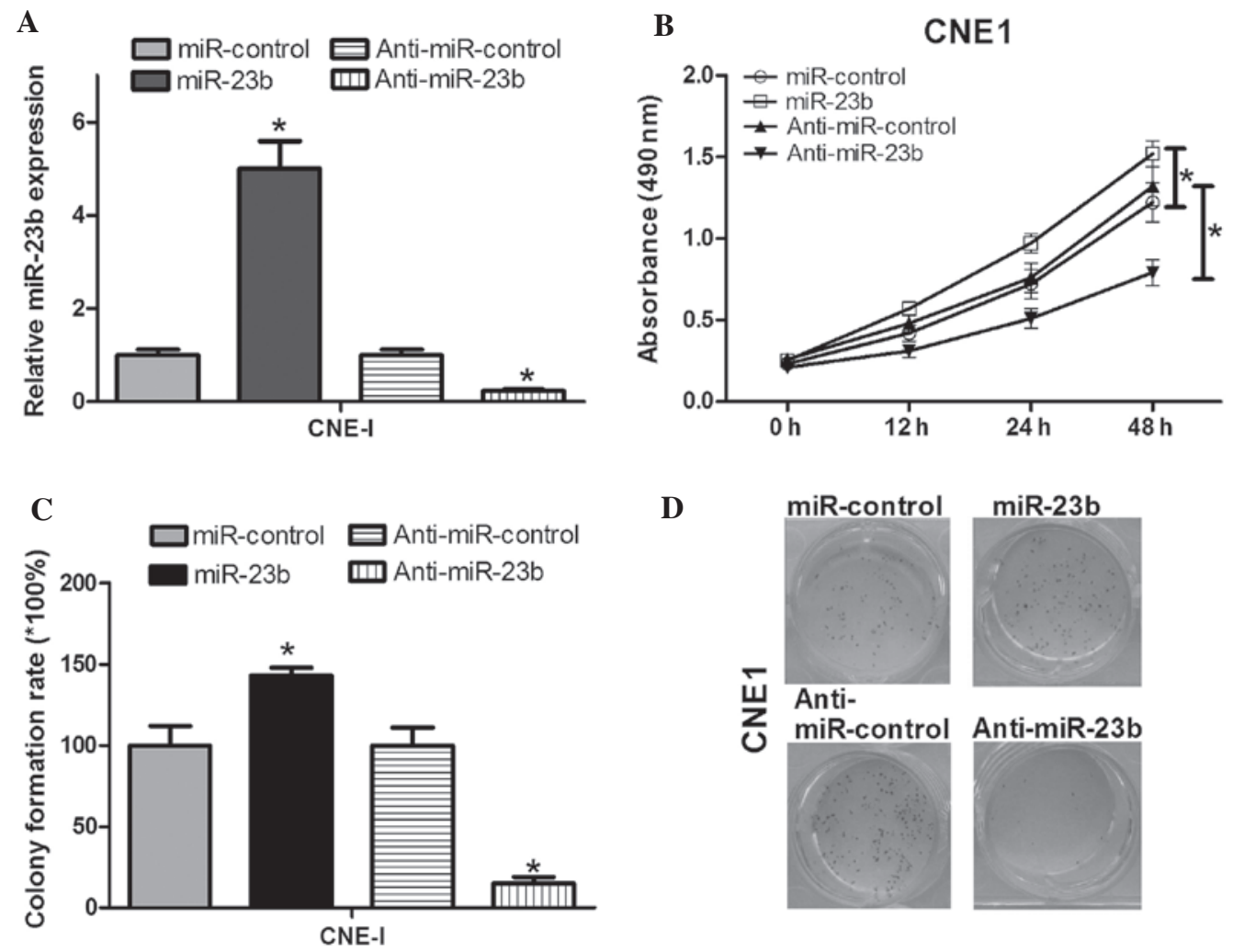

Figure 2. Overexpression of miR-23b enhances nasopharyngeal carcinoma cell proliferation. (A) The relative level of miR-23b expressed in CNE1 cells after transfection with miR-23b and anti-miR-23b. (B) CNE1 cells were transfected with miR-23b, anti-miR-23b or control vector. Cell growth activity was determined at 12, 24 and $48 \mathrm{~h}$ post-transfection using an MTT assay. Values are presented as the mean \pm standard deviation of three duplications and the relative cell growth activity is shown ("P $<0.05$, vs. the control). (C) The cell independent growth activity in vitro was assessed by colony formation assay. CNE1 cells were transfected with miR-23b, anti-miR-23b or control vector, and then seeded in 6-well plates. Colonies were counted only if they contained $>50$ cells, and the number of colonies was counted from the 6th day after seeding. The colony formation rate was calculated and was shown ("P<0.05). (D) The colony formation assay was shown. miR, microRNA.

cat. no. ab1416; Abcam, Cambridge, UK) and monoclonal mouse anti-human GAPDH (1:1,000; cat. no. ab8245; Abcam). After four washes with TBST, the filters were incubated with polyclonal goat anti-mouse peroxidase-conjugated secondary antibody (Sigma-Aldrich, Carlsbad, CA, USA) in 5\% skimmed milk in TBST solution for $1 \mathrm{~h}$ at room temperature. Reactions were developed using enhanced chemiluminiscence (Perkin Elmer, Waltham, MA, USA).

Cell proliferation assay. CNE1 cells were seeded in a 96-well plate at 8,000 cells per well the day prior to transfection. The cells were transfected with $0.2 \mu \mathrm{g} /$ well miR-23b, anti-miR-23b or control vector (Gene Pharma, Shanghai, China). An MTT assay was used to measure the number of viable, proliferating cells at 12, 24 and $48 \mathrm{~h}$ after transfection. The absorbance at $570 \mathrm{~nm}$ was measured using a $\mu$ Quant Universal Microplate spectrophotometer (Bio-Tek Instruments Inc., Winooski, VT, USA).

Colony formation assay. After transfection, CNE1 cells were counted and seeded in 6-well plates (in triplicate) at 50,60 and 75 cells per well. Fresh culture medium was provided every three days. Colonies were counted only if they contained $>50$ cells, and the number of colonies was counted from the 6 th day after seeding and then the cells were stained using crystal violet (Beyotime Institute of Biotechnology, Shanghai,
China). The rate of colony formation was calculated with the equation: Colony formation rate $=$ (number of colonies $/$ number of seeded cells) x 100 .

Transwell assay. CNE1 cells $\left(2 \times 10^{5}\right)$ were transiently transfected with or without anti-miR-23b. Posttransfection (48 h), $1.5 \times 10^{5}$ cells were resuspended in $300 \mu \mathrm{l}$ serum free medium and seeded to the transwell of uncoated polycarbonate membranes with $8.0 \mu \mathrm{m}$ pores (BD Biosciences, Franklin Lakes, NJ, USA) with the bottom supplemented with $800 \mu 1$ complete medium (Gibco-BRL). After $20 \mathrm{~h}$ incubation, cells that had migrated to the other side of the Transwell chamber were stained with $0.005 \%$ crystal violet. Ten images were randomly captured using an IX71 microscope (Olympus Corporation, Tokyo, Japan) and the cells were counted.

Enhanced green fluorescent protein (EGFP) reporter assay. Cells were cotransfected with miR-23b mimics or miR-23b control, together with a pcDNA3/EGFP-E-cadherin 3'-untranslated region (UTR) or a mutant UTR with a 4 base mutation in the complementary reporter vector seed sequence (all Guangzhou RiboBio Co., Ltd.). The pDsRed2-N1 red fluorescent protein (RFP) expression vector (Clontech Laboratories, Inc., Mountain View, CA, USA) was used as an internal control. A total of $48 \mathrm{~h}$ post-transfection, the cells were lysed with radioimmunoprecipitation assay lysis buffer $(150 \mathrm{mM}$ 

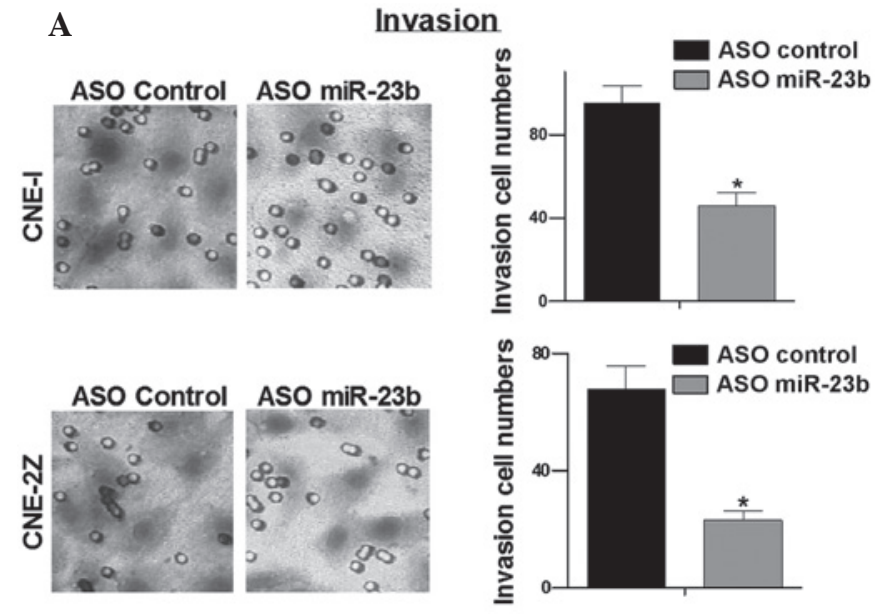

B

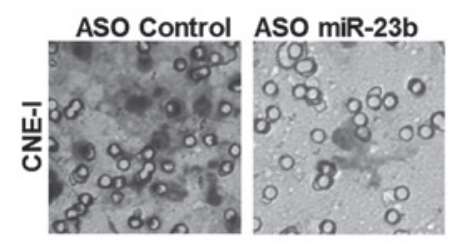

Migration
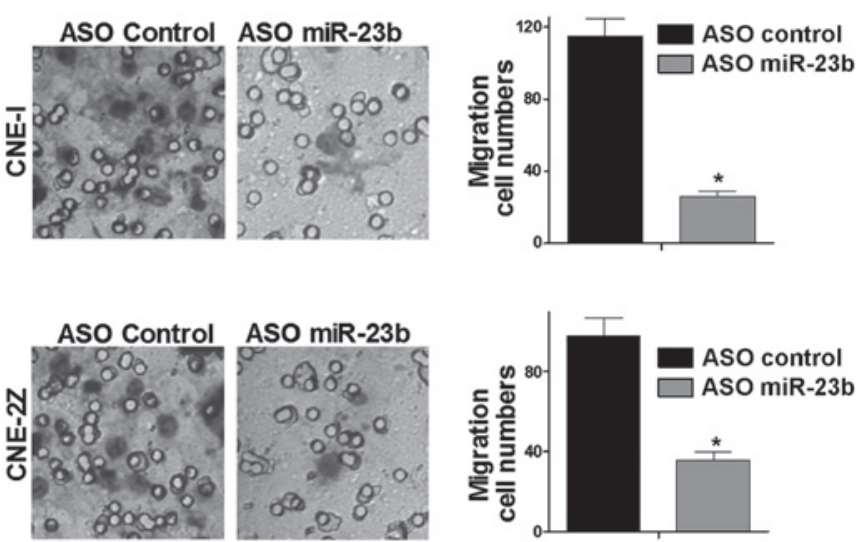

Figure 3. Low expression of miR-23b inhibits cell migration and invasion in nasopharyngeal carcinoma cells. ASO miR-23b was used to downregulate miR-23b expression levels. (A) Transwell analysis of CNE1 and CNE2Z cells after treatment with miR-23b inhibitors or control. The relative ratio of invasive cells per field is shown below ( $\mathrm{P}<0.05)$. (B) Transwell analysis of $\mathrm{CNE} 1$ and $\mathrm{CNE} 2 \mathrm{Z}$ cells after treatment with miR-23b inhibitors or control. The relative ratio of migrated cells per field is shown below ( $\mathrm{P}<0.05)$. miR, microRNA

$\mathrm{NaCl}, 50$ mM Tris- $\mathrm{HCl}$ pH 8.0, 1\% Triton X-100, 0.1\% SDS; Thermo Fisher Scientific, Inc., Waltham, MA, USA) to isolate the proteins. EGFP and RFP intensity was subsequently detected using an F-4500 fluorescence spectrophotometer (Hitachi, Ltd., Tokyo, Japan).

Statistical analysis. Data are expressed as the mean \pm standard deviation. $\mathrm{P}<0.05$ was considered to indicate a statistically significant difference. Students-Newman-Keuls test was used to determine significance. The data were analyzed using SPSS 17.0 (SPSS Inc., Chicago, IL, USA).

\section{Results}

miR-23b expression level in human NPC and the correlation with clinicopathological characteristics. RT-qPCR was used to detect differential expression of miR-23b in 17 paired samples of human NPC tissue and corresponding adjacent normal tissues. The results showed that the expression of miR-23b in NPC was significantly higher than that in the corresponding adjacent normal tissues (Fig. 1A). Staging of NPC is based on clinical and radiological examination. The majority of patients present with stage III or IV disease. A higher level of expression of miR-23b was associated with pathological tumor-node-metastasis stage (Fig. 1B), and a higher level of miR-23b was associated with $\mathrm{pM}$ stage $(\mathrm{P}<0.05$, metastasis vs. no metastssis) in patients with NPC (Fig. 1C). These data suggested that changes in the expression of miR-23b could be involved in NPC progression.

Overexpression of miR-23b enhances NPC cell proliferation. In order to investigate the effects of miR-23b on NPC cell proliferation, the miR-23b expression vector was constructed. After transfection of CNE1 cells, the validity of miR-23b and anti-miR-23b ectopic expression was determined by RT-qPCR. The results revealed that the miR-23b expression level was significantly higher in the miR-23b group than in the control group (Fig. 2A). In addition, anti-miR-23b could downregulate the miR-23b expression level. To test the effects of miR-23b on NPC cell proliferation, cell growth was investigated by an MTT assay and it was demonstrated that miR-23b could enhance CNE1 cell growth (Fig. 2B). A colony formation assay was conducted to further confirm the effects of miR-23b on cell proliferation. The colony formation rate of CNE1 cells transfected with anti-miR-23b was significantly lower than that of the control group (Fig. 2C). In addition, the colony formation rate of CNE1 cells transfected with miR-23b was significantly higher than the control group (Fig. 2C). These two experiments showed that miR-23b was involved in enhancing the cell growth and proliferation of NPC cells. Downregulating miR-23b resulted in the inhibition of cell viability and proliferation.

Low expression of miR-23b inhibits cell migration and invasion of NPC cells. To test whether low expression of miR-23b affects cancer cell migration and invasion, Transwell assays were performed. Transwell assays demonstrated that low expression of miR-23b significantly reduced the migration and invasion capacity of NPC cells (Fig. 3). These data demonstrated that low expression of miR-23b suppressed migration and invasion of NPC cell lines.

miR-23b directly targets the E-cadherin 3'-untranslated region (UTR) in NPC cells. To determine the target gene mediating the function of miR-23b, bioinformatics methods were used to predict potential target genes. It was identified that the 3'UTR of E-cadherin mRNA contains miR-23b complementary binding sites (Fig. 4A). To validate that E-cadherin can be directly targeted by miR-23b, an EGFP reporter assay was performed using engineered EGFP reporter vectors that had either the wild-type 3'UTR of E-cadherin or a mutant UTR with a 4-base mutation in the complementary seed sequence (Fig. 4A). pDsRed2-NI was also cotransfected for normalization. After CNE1 cells were cotransfected with pGL3-E-cadherin-WT and miR-23b mimics or miR-control, overexpression of miR-23b significantly repressed EGFP expression, compared with the control group (Fig. 4B). By contrast, EGFP expression levels by mutants of E-cadherin 3'UTR binding sites were not influenced by overexpression of miR-23b (Fig. 4B), indicating that miR-23b could bind to the specific sites of the E-cadherin mRNA 3'UTR and negatively regulate the expression of the E-cadherin gene. 
A

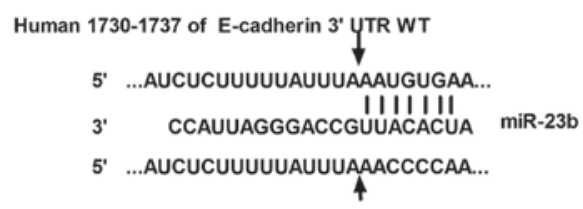

Human 1730-1737 of E-cadherin 3' UTR MUT

B

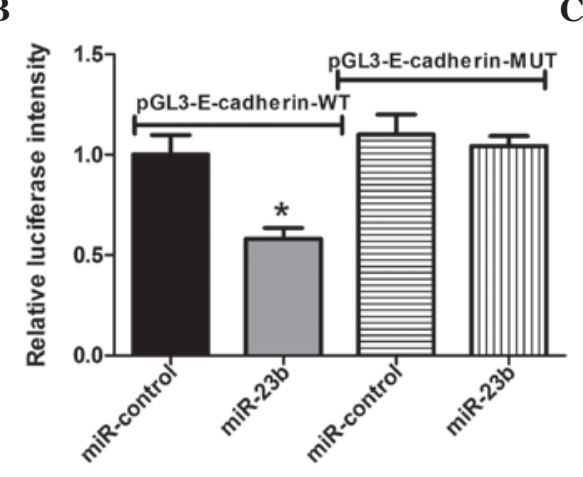

C

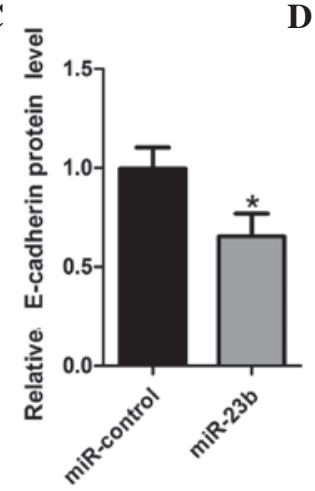

D

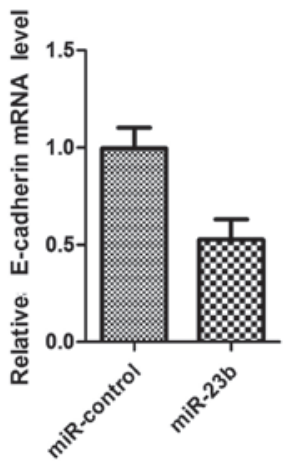

Figure 4. E-cadherin is a direct target gene of miR-23b. (A) The predicted binding sites of miR-23b on E-cadherin mRNA are shown. The mutant UTR with a four base pair for site-directed mutagenesis in the complementary seed sequences. (B) CNE1 cells were transfected with pGL3-E-cadherin-WT reporter vector as well as miR-23b or control vector. miR-23b suppressed the EGFP fluorescence intensity of pGL3-E-cadherin-WT ("P<0.05); however, no suppression was observed in the group transfected with pGL3-E-cadherin-MUT. (C) CNE1 cells were transfected with miR-23b and control vector, the E-cadherin protein expression level was evaluated by western blot analysis. GAPDH protein was regarded as endogenous normalizer and the relative E-cadherin protein quantity is shown $(" \mathrm{P}<0.05)$. (D) CNE1 cells were transfected with miR-23b and control vector, the expression of E-cadherin mRNA was measured by reverse transcription-quantitative polymerase chain reaction. $\beta$-actin mRNA was regarded as an endogenous normalizer and the relative E-cadherin mRNA expression level is shown ("P<0.05). miR, microRNA; UTR, untranslated region; WT, wild type; EGFP, enhanced green fluorescent protein; MUT, mutant.

A

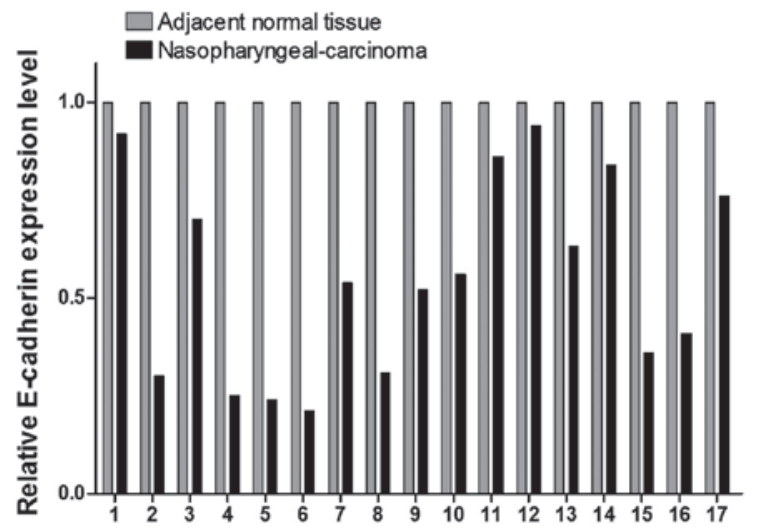

B

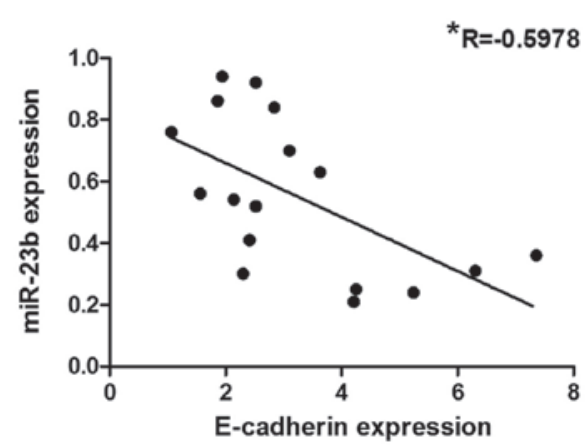

Figure 5. Identification of differential expression of E-cadherin in human nasopharyngeal carcinoma. (A) Western blotting was used to measure E-cadherin expression in 17 pairs of human nasopharyngeal carcinoma and corresponding adjacent normal tissues. (B) The expression level of E-cadherin had a negative correlation with miR-23b expression. The expression levels of each normal tissue sample was normalized to the corresponding nasopharyngeal carcinoma. miR, microRNA.

miR-23b exhibits a negative regulatory role at the E-cadherin posttranscriptional level. miRNAs regulate target genes at the post-transcriptional level by binding their target genes 3'UTR to silence the gene function (40). CNE1 cells were transfected with miR-23b in order to examine whether miR-23b depresses endogenous E-cadherin expression through translational repression, the expression of E-cadherin protein was examined by western blotting. The results showed that overexpression of miR-23b resulted in a decrease in the expression level of E-cadherin protein (Fig. 4C), suggesting that miR-23b negatively regulates endogenous E-cadherin protein expression through a translational repression mechanism. Furthermore, a high expression level of miR-23b in CNE1 cells also decreased the endogenous E-cadherin mRNA level (Fig. 4D). In the 17 pairs of NPC tissues, the expression level of E-cadherin in NPC tissues was identified to be significantly lower than that in the matched adjacent normal tissues (Fig. 5A). The expression level of E-cadherin was negatively correlated with miR-23b expression (Fig. 5B). These data suggest that miR-23b negatively regulates the expression of E-cadherin through mRNA cleavage at the post-transcriptional level.

\section{Discussion}

Transformation of malignant tumors is regulated by the synergy of multiple genes, including overexpression of oncogenes and 
low expression or even loss of function of tumor suppressor genes. Recent studies have demonstrated that the regulation of oncogenes and tumor suppressor genes not only occurred at the transcriptional level, but also at the post-transcriptional level. miRNAs, as important regulatory factors, are involved in the altered gene expression that occurs in human carcinogenesis. In recent years, miRNA-mediated post-transcriptional gene silencing and its relevance in tumor formation have become the focus of attention in miRNA research. Tumor cells and normal cells have significantly different in miRNA expression profiles. The majority of miRNA genes are located in chromosomal regions that frequently display amplification, deletion or translocation in human cancer. In cancer, miRNA genes that appear in high frequency are closely associated with variability of the genome, suggesting that miRNAs may participate in cancer development and progression. Detection of differential expression of miRNAs in human NPC may determine the role of miRNAs in cancer and function of their target genes, and provide a novel direction for the diagnosis and treatment of human NPC.

The present study aimed to identify a novel miRNA that regulates the expression of E-cadherin, and evaluate its effects on cell phenotype using NPC cells. Initially, RT-qPCR was conducted and demonstrated that miR-23b was significantly upregulated in human NPC tissue, compared with the adjacent normal tissue. The results suggested that miR-23b may be important in the development of human NPC. Therefore, it was hypothesized that miR-23b was a positive factor in carcinogenesis in human NPC cells due to high expression levels of miR-23b in human NPC tissue. Cell growth viability was determined using the MTT assay to detect the correlation between miR-23b and the growth capacity of CNE1 NPC cells. The cell growth viability of CNE1 cells transfected with anti-miR-23b was significantly decreased when compared with the control group (Fig. 2B). Moreover, overexpression of miR-23b increased cell growth and viability when compared with the control group (Fig. 2B). It was also demonstrated that low expression of miR-23b significantly reduced the migration and invasion capacity of NPC cells (Fig. 3A and B).

Secondly, bioinformatics analyses predicted an miR-23b binding site on the E-cadherin transcript (Fig.4A).Experimental evidence indicated that E-cadherin was a target of miR-23b. The ability of miR-23b to regulate E-cadherin expression was likely direct as it bound to the 3'UTR of E-cadherin mRNA complementarily to the miR-23b seed region. The EGFP fluorescence intensity of pGL3-E-cadherin-WT was specifically responsive to miR-23b overexpression (Fig. 4B). However, mutation of the miR-23b binding site abolished the effect of miR-23b on the regulation of EGFP fluorescence intensity (Fig. 4B). Conversely, endogenous E-cadherin protein expression was decreased in CNE1 cells transfected with miR-23b, while it was increased in CNE1 cells transfected with anti-miR-23b (Fig. 4C). In addition, it was observed that the change in miR-23b expression effected the E-cadherin mRNA level. These results suggested that miR-23b regulated E-cadherin protein expression.

E-cadherin is a classical member of the cadherin superfamily. Cadherins comprise of a family of calcium-dependent adhesion glycoproteins that mediate cell-cell binding to maintain differentiated tissue structure and morphogenesis. Loss of E-cadherin function or expression has been implicated in cancer progression and metastasis (41). Downregulation of E-cadherin decreases the strength of cellular adhesion within a tissue, resulting in an increase in cellular motility. This in turn may allow cancer cells to cross the basement membrane and invade surrounding tissues.

In conclusion, it was demonstrated that miR-23b is important in the regulation of E-cadherin gene expression. The effect of miRNAs on NPC cell expression occurred at the mRNA and transcriptional levels, and at least in part through targeting E-cadherin. However, miR-23b may be capable of controlling tumor-specific gene(s), consequently favoring cell growth and migration. Therefore, this study suggests that targeting miR-23b may provide a promising strategy for inhibiting tumor proliferation and metastasis.

\section{References}

1. Zhang F and Zhang J: Clinical hereditary characteristics in nasopharyngeal carcinoma through Ye-Liang's family cluster. Chin Med J (Engl) 112: 185-187, 1999.

2. Wei WI and Sham JS: Nasopharyngeal carcinoma. Lancet 365: 2041-2054, 2005.

3. Cao SM, Simons MJ and Qian CN: The prevalence and prevention of nasopharyngeal carcinoma in China. Chin J Cancer 30: 114-119, 2011.

4. Lo KW, Chung GT and To KF: Deciphering the molecular genetic basis of NPC through molecular, cytogenetic, and epigenetic approaches. Semin Cancer Biol 22: 79-86, 2012

5. Feng BJ, Huang W, Shugart YY, Lee MK, Zhang F, Xia JC, Wang HY, Huang TB, Jian SW, Huang P, et al: Genome-wide scan for familial nasopharyngeal carcinoma reveals evidence of linkage to chromosome 4. Nat Genet 31: 395-399, 2002.

6. Zhou G, Zhai Y, Cui Y, Zhang X, Dong X, Yang H, He Y, Yao K, Zhang H, Zhi L, et al: MDM2 promoter SNP309 is associated with risk of occurrence and advanced lymph node metastasis of nasopharyngeal carcinoma in Chinese population. Clin Cancer Res 13: 2627-2633, 2007.

7. Calin GA, Sevignani C, Dumitru CD, Hyslop T, Noch E, Yendamuri S, Shimizu M, Rattan S, Bullrich F, Negrini M and Croce CM: Human microRNA genes are frequently located at fragile sites and genomic regions involved in cancers. Proc Natl Acad Sci USA 101: 2999-3004, 2004.

8. Takamizawa J, Konishi H, Yanagisawa K, Tomida S, Osada H, Endoh H, Harano T, Yatabe Y, Nagino M, Nimura Y, et al: Reduced expression of the let-7 microRNAs in human lung cancers in association with shortened postoperative survival. Cancer Res 64: 3753-3756, 2004.

9. Yanaihara N, Caplen N, Bowman E, Seike M, Kumamoto K, Yi M, Stephens RM, Okamoto A, Yokota J, Tanaka T, et al: Unique microRNA molecular profiles in lung cancer diagnosis and prognosis. Cancer Cell 9: 189-198, 2006.

10. Johnson SM, Grosshans H, Shingara J, Byrom M, Jarvis R, Cheng A, Labourier E, Reinert KL, Brown D and Slack FJ: RAS is regulated by the let-7 microRNA family. Cell 120: 635-647, 2005.

11. Lee YS and Dutta A: The tumor suppressor microRNA let-7 represses the HMGA2 oncogene. Genes Dev 21: 1025-1030, 2007.

12. Felli N, Fontana L, Pelosi E, Botta R, Bonci D, Facchiano F, Liuzzi F, Lulli V, Morsilli O, Santoro S, et al: MicroRNAs 221 and 222 inhibit normal erythropoiesis and erythroleukemic cell growth via kit receptor down-modulation. Proc Natl Acad Sci USA 102: 18081-18086, 2005.

13. Visone R, Russo L, Pallante P, De Martino I, Ferraro A, Leone V, Borbone E, Petrocca F, Alder H, Croce CM and Fusco A: MicroRNAs (miR)-221 and miR-222, both overexpressed in human thyroid papillary carcinomas, regulate p27Kip1 protein levels and cell cycle. Endocr Relat Cancer 14: 791-798, 2007.

14. Chou CK, Chen RF, Chou FF, Chang HW, Chen YJ, Lee YF, Yang KD, Cheng JT, Huang CC and Liu RT: MiR-146b is highly expressed in adult papillary thyroid carcinomas with high risk features including extrathyroidal invasion and the BRAF (V600E) mutation. Thyroid 20: 489-494, 2010. 
15. Voorhoeve PM, le Sage C, Schrier M, Gillis AJ, Stoop H, Nagel R, Liu YP, van Duijse J, Drost J, Griekspoor A, et al: A genetic screen implicates miRNA-372 and miRNA-373 as oncogenes in testicular germ cell tumors. Cell 124: 1169-1181, 2006.

16. Chan JA, Krichevsky AM and Kosik KS: MicroRNA-21 is an antiapoptotic factor in human glioblastoma cells. Cancer Res 65: 6029-6033, 2005.

17. Zhu S, Si ML, Wu H and Mo YY: MicroRNA-21 targets the tumor suppressor gene tropomyosin 1 (TPM1). J Biol Chem 282: 14328-14336, 2007

18. Si ML, Zhu S, Wu H, Lu Z, Wu F and Mo YY: MiR-21-mediated tumor growth. Oncogene 26: 2799-2803, 2007.

19. Li J, Huang H, Sun L, Yang M, Pan C, Chen W, Wu D, Lin Z, Zeng C, Yao Y, et al: MiR-21 indicates poor prognosis in tongue squamous cell carcinomas as an apoptosis inhibitor. Clin Cancer Res 15: 3998-4008, 2009.

20. Cimmino A, Calin GA, Fabbri M, Iorio MV, Ferracin M, Shimizu M, Wojcik SE, Aqeilan RI, Zupo S, Dono M, et al: MiR-15 and miR-16 induce apoptosis by targeting BCL2. Proc Natl Acad Sci USA 102: 13944-13949, 2005.

21. Xia L, Zhang D, Du R, Pan Y, Zhao L, Sun S, Hong L, Liu J and Fan D: MiR-15b and miR-16 modulate multidrug resistance by targeting BCL2 in human gastric cancer cells. Int J Cancer 123: 372-379, 2008

22. He L, Thomson JM, Hemann MT, Hernando-Monge E, Mu D Goodson S, Powers S, Cordon-Cardo C, Lowe SW, Hannon GJ and Hammond SM: A microRNA polycistron as a potential human oncogene. Nature 435: 828-833, 2005.

23. Matsubara H, Takeuchi T, Nishikawa E, Yanagisawa K, Hayashita Y, Ebi H, Yamada H, Suzuki M, Nagino M, Nimura Y, et al: Apoptosis induction by antisense oligonucleotides against miR-17-5p and miR-20a in lung cancers overexpressing miR-17-92. Oncogene 26: 6099-6105, 2007.

24. Fish JE, Santoro MM, Morton SU, Yu S, Yeh RF, Wythe JD, Ivey KN, Bruneau BG, Stainier DY and Srivastava D: MiR-126 regulates angiogenic signaling and vascular integrity. Dey Cell 15: 272-284, 2008 .

25. Wang S, Aurora AB, Johnson BA, Qi X, McAnally J, Hill JA, Richardson JA, Bassel-Duby R and Olson EN: The endothelial-specific microRNA miR-126 governs vascular integrity and angiogenesis. Dev Cell 15: 261-271, 2008.

26. Kuhnert F, Mancuso MR, Hampton J, Stankunas K, Asano T, Chen CZ and Kuo CJ: Attribution of vascular phenotypes of the murine Egfl7 locus to the microRNA miR-126. Development 135: 3989-3993, 2008

27. Dews M, Homayouni A, Yu D, Murphy D, Sevignani C, Wentzel E, Furth EE, Lee WM, Enders GH, Mendell JT and Thomas-Tikhonenko A: Augmentation of tumor angiogenesis by a Myc-activated microRNA cluster. Nat Genet 38: 1060-1065, 2006.
28. Würdinger T, Tannous BA, Saydam O, Skog J, Grau S, Soutschek J, Weissleder R, Breakefield XO and Krichevsky AM: MiR-296 regulates growth factor receptor overexpression in angiogenic endothelial cells. Cancer Cell 14: 382-393, 2008.

29. Poliseno L, Tuccoli A, Mariani L, Evangelista M, Citti L, Woods K, Mercatanti A, Hammond S and Rainaldi G: MicroRNAs modulate the angiogenic properties of HUVECs. Blood 108: 3068-3071, 2006.

30. Kuehbacher A, Urbich C, Zeiher AM and Dimmeler S: Role of dicer and drosha for endothelial microRNA expression and angiogenesis. Circ Res 101: 59-68, 2007.

31. Xu N, Papagiannakopoulos T, Pan G, Thomson JA and Kosik KS: MicroRNA-145 Regulates OCT4, SOX2 and KLF4 and represses pluripotency in human embryonic stem cells. Cell 137: 647-658, 2009.

32. Di Leva G, Calin GA and Croce CM: MicroRNAs: Fundamental facts and involvement in human diseases. Birth Defects Res C Embryo Today 78: 180-189, 2006.

33. Chen CZ, Li L, Lodish HF and Bartel DP: MicroRNAs modulate hematopoietic lineage differentiation. Science 303: 83-86, 2004.

34. Ma L, Young J, Prabhala H, Pan E, Mestdagh P, Muth D, Teruya-Feldstein J, Reinhardt F, Onder TT, Valastyan S, et al: MiR-9, a MYC/MYCN-activated microRNA, regulates E-cadherin and cancer metastasis. Nat Cell Biol 12: 247-256, 2010.

35. Iorio MV, Ferracin M, Liu CG, Veronese A, Spizzo R, Sabbioni S, Magri E, Pedriali M, Fabbri M, Campiglio M, et al: MicroRNA gene expression deregulation in human breast cancer. Cancer Res 65: 7065-7070, 2005

36. Yanaihara N, Caplen N, Bowman E, Seike M, Kumamoto K, Yi M, Stephens RM, Okamoto A, Yokota J, Tanaka T, et al: Unique microRNA molecular profiles in lung cancer diagnosis and prognosis. Cancer Cell 9: 189-198, 2006.

37. Gramantieri L, Ferracin M, Fornari F, Veronese A, Sabbioni S, Liu CG, Calin GA, Giovannini C, Ferrazzi E, Grazi GL, et al: Cyclin G1 is a target of miR-122a, a microRNA frequently down-regulated in human hepatocellular carcinoma. Cancer Res 67: 6092-6099, 2007.

38. Chinese Committee for Staging of Nasopharyngeal Carcinoma: Report on revision of the Chinese 1992 staging system for nasopharyngeal carcinoma. J Radiat Oncol 3: 233-240, 2013

39. Hou F, Wang L, Wang H, Gu J, Li M, Zhang J, Ling X, Gao X and Luo C: Elevated gene expression of S100A12 is correlated with the predominant clinical inflammatory factors in patients with bacterial pneumonia. Mol Med Rep 11: 4345-4352, 2015.

40. Gregory RI and Shiekhattar R: MicroRNA biogenesis and cancer. Cancer Res 65: 3509-3512, 2005.

41. Shirakawa T, Miyahara Y, Tanimura K, Morita H, Kawakami F, Itoh $\mathrm{T}$ and Yamada $\mathrm{H}$ : Expression of epithelial-mesenchymal transition-related factors in adherent placenta. Int J Gynecol Pathol 34: 584-589, 2015. 